\title{
O PERCURSO DÂNDI DE PARIS A TORMES EM A CIDADE E AS SERRAS, DE EÇA DE QUEIROZ
}

Lúcia Trindade Valente Pesquisadora Independente Júnia de Castro Magalhães Alves Universidade Federal de Minas Gerais Unicentro Newton Paiva

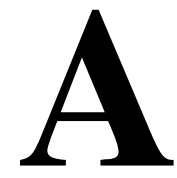

segunda metade do século XIX é marcada por uma diversidade literária, conseqüência dos vários movimentos políticos, econômicos e sociais que visavam a mudanças e propunham novas formas de organização das nações. Levantes populares ou patrióticos rompem na Áustria, França, Itália, Alemanha do Norte, na Rússia e na Prússia, reforçando as idéias de Karl Marx e Friedrich Engels, publicadas em 1848 no Manifesto do Partido Comunista, que glorificava a organização da classe operária e a união dos cidadãos pobres de todos os países.

Do ponto de vista sócio-econômico, a revolução industrial suscita o nascimento de um grupo novo: o proletariado urbano. Em contraste com essa classe desfavorecida, a grande burguesia concentra a riqueza e os instrumentos de produção, dominando o sistema. Já do ponto de vista político, essa mesma burguesia rica e ativa vê-se obrigada a dividir o poder adquirido com as autoridades tradicionais, aristocracia e clero, que conservavam parte da influência e do prestígio que possuíram no século XVIII.

Entretanto, após 1848 ressurge, ou se perpetua, em alguns países europeus acima mencionados, a tirania centralizada, que se distinguia por princípios autocráticos ilimitados e por uma sociedade marcada por sérias injustiças econômicas e políticas. Já na Inglaterra e na França, verifica-se o triunfo burguês. A prosperidade crescente refletese na literatura. 
Em Portugal, trava-se, nessa época, uma luta ferrenha entre duas forças sociais e políticas: a pequena burguesia radical e o capitalismo latifundiário e financeiro, cuja manifestação literária se traduz, em primeira instância, pela geração romântica (1825-1865). Nos anos seguintes a 1860, desencadeia-se uma profunda mudança na literatura portuguesa - caracterizada pela concepção do mundo, própria das ciências naturais e do pensamento racionalista-tecnológico referente ao idealismo e à tradição romântica. Por decorrência, os trabalhos literários derivam seus critérios para a construção de um universo ficcional regido pela probabilidade cientifica do realismo. É uma das épocas mais ricas da prosa lusitana. Entre seus representantes destaca-se José Maria Eça de Queiroz (1845-1900), reconhecido pelo estilo esmerado que, segundo críticos, permitiu a Portugal uma recuperação de vários decênios de atraso em relação à França e à Inglaterra. A intertextualidade lingüística e temática de sua obra, com a literatura desses dois países, é facilmente visível.

Eça de Queiroz, tendo sido diplomata, viveu em ambiente elitista, entre viagens e compromissos sociais. Retratou, com meticulosidade e precisão, a geografia assim como a sociedade européia e, mais particularmente, a portuguesa do século XIX, por meio de narrativa, descrição e argumentação astuciosas. Criou personagens irresistíveis, dotados de contradições e conflitos próprios da natureza humana, personagens esses que, por vezes e como é natural, refletiam o comportamento elegante e as prioridades comportamentais do escritor. Os biógrafos observam nele uma postura apurada e distinta, um certo dandismo descrito, sobretudo, como manifestação de seu espírito aristocrático. Essa qualidade, exposta em vários momentos de sua escritura, será, aqui, focalizada no romance $A$ cidade e as serras, publicado postumamente em 1901. O mesmo tema aparecera antes, em 1892, no conto "Civilização". Em ambos os textos o elemento dândi é prioritário e fundamental no desenvolvimento da ação, uma vez que exerce prática determinante do enredo.

Segundo verbete do dicionário A Handbook to Literature de C. Hugh Holman, "O dandismo é um estilo literário usado pelos 
escritores ingleses e franceses no último quarto do século XIX. O termo, derivado de dandy, descreve aquele que supervaloriza a vestimenta e a aparência pessoal. Como estilo literário é marcado por emoções excessivamente refinadas e pela preciosidade da linguagem." ${ }^{1}$ Etimologicamente não se sabe com exatidão de onde essa palavra surgiu. Poderia ter sido do verbo francês se dandiner, que significa balançar o corpo de uma maneira desajeitada e displicente. Poderia ainda derivar-se do sânscrito, danda, que significa bengala. Fundado sobre privilégios ancestrais e estatutários, o dandismo é um regime de comportamento ético e estético que subordina antigos valores a novos princípios emanados do pensamento iluminista do século XVIII - um mérito pessoal, uma nobreza de espírito e de aparência.

De acordo com os teóricos do dandismo que estão citados neste trabalho, o primeiro dândi moderno foi o inglês George Brummell (O Belo Brummell, 1778-1840). As histórias contadas a respeito de sua elegância concederam-lhe fama inigualável. A lenda diz que trocava de indumentária três vezes ao dia, obedecendo a um ritual de três horas a cada sessão. Cerca de outras três horas diárias eram dedicadas ao aconselhamento com seu alfaiate, ou com o funcionário responsável por seu guarda-roupa. Brummell introduziu na Inglaterra os novos códigos de honra e de distinção, dentro de uma sociedade em plena decadência. Apesar de suas origens humildes, George IV, Rei da Inglaterra, adotou-o como seu orientador de moda. O segundo foi seu amigo Lorde Byron (17881824). Esse aristocrata inglês fascinou o mundo, não só com sua obra poética, mas também com uma atitude livre, aventureira e requintada. Pessoas famosas da sociedade londrina do século XIX elegeram-no seu modelo. Com Lorde Byron a ideologia dândi atravessou o Canal e conquistou a burguesia francesa, numa onda de anglomania, freqüentemente levada a extremos.

Segundo Charles Baudelaire, o dandismo é uma religião, um culto racional que singulariza o indivíduo, não somente pela

${ }^{1}$ HOLMAN, 1980. p.119. 
vestimenta, mas também, pela seriedade moral e pelo comportamento sócio-político correto. Ser dândi não é somente uma maneira de vestir. É também uma atitude de vida. O dândi não é como os outros. É um homem superior no que se refere a alguns predicados fundamentais, tais como, nascimento em berço de ouro, distinção física, autoconcentração, senso estético e do bem-estar. O dandismo verdadeiro resulta de um temperamento artístico e metódico, trabalhando um corpo refinado dentro dos limites da moda. Em seu estudo sobre Constantin Guys, O pintor da vida moderna, Baudelaire consagra um capítulo inteiro à filosofia em questão:

O dandismo é uma instituição vaga tão estranha como o próprio duelo; muito antiga (...) e generalizada. O dandismo, instituição à margem das leis, tem leis rigorosas a que são estritamente submetidos todos os seus adeptos, quaisquer que forem, aliás, a audácia e a independência de seu caráter. (...) Um dândi pode ser um homem entediado, pode ser um homem que sofre; mas, neste último caso, ele sorrirá como o Lacedemônio mordido pela raposa. ${ }^{2}$

É a partir dessa noção antitética e paradoxal do dandismo ideológico, do seu caráter de rejeição às leis gerais e obediência às suas próprias leis, que se propõe estudar o elemento dândi, no personagem Jacinto, do romance $A$ cidade e as serras, de Eça de Queiroz. Tendo em vista a dimensão e a complexidade desse objeto, não será possível uma análise exaustiva do assunto, mas buscar-se-ão imagens do dândi na obra, visando a estabelecer sua manifestação literária. Embora correndo o risco de uma indiscutível tendência à simplificação, o trabalho de organizar esse esboço é sedutor, pelo exercício de detida observação e esforço interpretativo.

Serão focalizadas em Jacinto de Tormes, protagonista do romance, as expressões de superposição e semelhança - quanto à origem, aparência, comportamento político e social na Europa, na segunda metade do século XIX - com as do dândi baudelairiano, embora caiba aqui demonstrar que ele apresenta uma identidade

${ }^{2}$ BAUDELAIRE, 1996. p.47-49. 
indubitavelmente lusitana e que não pode ser visto como um mero estereótipo do fenômeno em questão. E é, pois, nesse contexto de fim de século que "O meu amigo Jacinto nasceu num palácio, com cento e nove contos de renda em terras de semeadura, de vinhedo, de cortiça e de olival". ${ }^{3}$

Como se lê, o protagonista de $A$ cidade e as serras, seguindo o exemplo do dândi descrito por Baudelaire, descende de antepassados de alta linhagem, em seu caso, portugueses. Ele é o último brilho do heróico em tempos de decadência, motivo composicionalassociado, isto é, imprescindível para o desencadear da mudança geográfica e psicológica, de Paris a Tormes, contido no desenrolar da história:

Desde o berço (...) Jacinto medrou com a segurança, a rijeza, a seiva rica de um pinheiro das dunas. Não teve sarampo, e não teve lombrigas. As letras, a tabuada, o latim entraram por ele tão facilmente como o sol por uma vidraça (...) Rijo, rico, indiferente ao Estado e ao Governo dos homens, nunca lhe conhecemos outra ambição além de compreender bem as idéias gerais (...).

Por isso nós lhe chamávamos o Principe da Grã-Ventura. ${ }^{4}$

A citação comprova que o herói é "aristocrata" por nascimento e pelo título que lhe confere o personagem narrador da história, José Fernandes. Sua aristocracia vincula-se tanto à saúde (pois não foi acometido por doenças comuns e cresceu como um soberbo moço em quem reaparecera a força dos velhos Jacintos rurais), quanto à origem sócio-econômica abastada; aos hábitos sociais refinados, tais como o vestuário, a alimentação, as formas de tratamento pessoal e de lazer; e à performance intelectual bem sucedida. É nobre de espírito e de aparência.

Inspirados pelo dandismo, romancistas do século XIX, como Flaubert, Maupassant e Eça tiveram o cuidado de dotar suas criaturas de grandes fortunas, capazes de saciá-las em suas fantasias, dispen-

${ }^{3}$ QUEIROZ, [s.d.]. p.9.

${ }^{4}$ QUEIROZ, [s.d.]. p.10-11. 
sando-as de uma carreira profissional. A grande preocupação desses personagens era cultivar o belo, o conforto, a arte, a cultura. Seu habitat era a cidade e nela "a sociedade que os enredava em tradições, preceitos, etiquetas, cerimônias, praxes, ritos, serviços mais disciplinares que os de um cárcere e um quartel...". ${ }^{5}$ Possuíam o tempo e o dinheiro para viver edonisticamente, como Zé Fernandes nos conta:

No 202, todas as manhãs, às nove horas, depois do meu chocolate e ainda em chinelas, penetrava no quarto de Jacinto. Encontrava o meu amigo banhado, barbeado, friccionado, envolto num roupão branco de pelo de cabra do Tibete, diante de sua mesa de toilette, toda de cristal, (por causa dos micróbios) e atulhada com esses utensílios de tartaruga, marfim, prata, aço e madrepérola que o homem do século XIX necessita para não desfear o conjunto suntuário da civilização e manter nela o seu tipo. ${ }^{6}$

A partir dessas e outras observações, feitas com fina ironia pelo romancista, na voz do narrador-actante-personagem secundário, pode-se analisar a mesmice da cidade e a rotina de Jacinto. Religiosamente a cada dia, não havia acessório em sua indumentária que não simbolizasse o estado temperamental do herói, naquela ocasião. Mais ainda, sua supremacia dândi revelava-se no tato com que adaptava a toalete a seu temperamento. Em suas errâncias, privilegiando o quotidiano imposto pelo grupo que o rodeava, o protagonista de $A$ cidade e as serras levava uma vida fútil, vazia, mundana, antinatural, em busca de emoções que compensassem o embaraço de viver. Ocioso, caminhava altivo, marcando presença nas altas rodas, protestando contra as funções, trabalhos e cargos tradicionais que a sociedade determina para as classes populares.

Dessa forma, Jacinto encarna também o flaneur, que, segundo o teórico Walter Benjamin, ${ }^{7}$ é, para Baudelaire, "o homem das

${ }^{5}$ QUEIROZ, [s.d.]. p.48.

${ }^{6}$ QUEIROZ, [s.d.]. p.21-22.

${ }^{7}$ BENJAMIN, 1994. p.45. 
multidões”. Já para Edgar Alan Poe, fonte muitas vezes inspiradora do poeta francês, "The man of the crowd", ou seja, o homem que procura a multidão, é um inseguro em sua própria sociedade. Nessa trilha, embora sentisse "horror pela multidão", ${ }^{8}$ o protagonista de $A$ cidade e as serras vaga pelas ruas de Paris, sem compromissos com a labuta diária do cidadão comum:

Quando o dia social de Jacinto se apresentava mais desafogado (...) saíamos depois do almoço, a pé, através de Paris. Estes lentos e errantes passeios eram outrora, na nossa idade de estudantes, um gozo muito querido de Jacinto - porque neles mais intensamente e mais minuciosamente saboreava a cidade.?

Esse flaneur de sangue português, significativamente, sentese atraído pelo Bosque de Bolonha e pelo Jardim das Plantas, onde recupera as forças em um ato de consciência e se re-humaniza. Mas, em sua ambivalência, vê-se também seduzido pelos trabalhos arquitetônicos da estação ferroviária, dos pavilhões de exposições e das grandes lojas parisienses, corroborando a afirmação de Walter Benjamin que a cidade é, portanto, o autêntico chão sagrado da flanerie: "Paisagem - eis em que se transforma a cidade para o flaneur. Melhor ainda, para ele a cidade se cinde em seus pólos dialéticos. Abre-se para ele como paisagem e, como quarto, cinge-o". ${ }^{10}$

Contudo esse homem erradio distingue-se dos outros passantes pelo talhe da roupa, pelos calções apertados e pela escolha do colarinho virado para cima, firmado por um lenço em forma de plastron ou stock - uma faixa dura, em nó, já pronta e abotoada atrás. Essa indumentária tornava difícil, se não impossível, virar ou abaixar a cabeça, contribuindo para a aparente arrogância do dândi. As cartolas eram usadas em todas as ocasiões, mas o chapéu certo para a noite seria o bicorne, com formato de lua crescente. Os

${ }^{8}$ QUEIROZ, [s.d.]. p.24.

${ }^{9}$ QUEIROZ, [s.d.]. p.23.

${ }^{10}$ BENJAMIN, 1994. p.186. 
cabelos eram curtos, mas a moda determinava-os um pouco despenteados. Os civis barbeavam-se, mas os militares usavam costeletas e, ocasionalmente, bigode. O porte de espadas fora totalmente abolido e substituído pela bengala. Na verdade, nenhum homem distinto era visto na rua sem ela. Ironicamente, o dândi radiava austeridade. José Fernandes descreve bem esse retrato do amigo:

Adiante de mim caminhava, lentamente curvado, um homem que, desde as botas rebrilhantes até as abas recurvas do chapéu de onde fugiam anéis de um cabelo crespo, ressumava elegância e a familiaridade das coisas finas. Nas mãos, cruzadas atrás das costas, calçadas de anta branca, sustentava uma bengala grossa com castão de cristal. ${ }^{11}$

O uso do chapéu confirma a "superioridade" do dândi em Jacinto, uma vez que, na linguagem simbólica, esse acessório corresponde à coroa, metonímia do poder, da soberania da cabeça e do pensamento. Usar chapéu é assumir responsabilidades. A bengala, por sua vez, aparece inicialmente como símbolo de arma, uma arma encantada, que serve de apoio à marcha do peregrino ou do pastor. Apoio, defesa, guia, a bengala torna-se cetro, signo de autoridade, de realeza e de comando, tanto na ordem intelectual quanto na hierarquia social. Percebe-se também, nas descrições, que o narrador fornece outras referências comprobatórias do dandismo no herói português, como o penteado e o uso de luvas. Jacinto é aristocrático, estóico, elegante, reservado, por vezes inconscientemente egoísta, e disciplinado. Recorre ao exagero da higiene e da toalete para corromper a sua espontaneidade, numa ascese do artificial.

Além das características temporais (século XIX) e individuais descritas acima, relevante é o espaço, o ambiente e a paisagem em que nasce, cresce e estuda Jacinto:

Mas o palácio onde Jacinto nascera, e onde sempre habitara, era em Paris, nos Campos Elísios, no. 202. ${ }^{12}$

${ }^{11}$ QUEIROZ, [s.d.]. p.16.

${ }^{12}$ QUEIROZ, [s.d.]. p.9. 
Jacinto e eu, José Fernandes, ambos nos encontramos e acamaradamos em Paris, nas escolas do Bairro Latino (...). ${ }^{13}$

Por uma conclusão bem natural, a idéia de civilização, para Jacinto, não se separava da imagem de cidade, de uma enorme cidade, com todos os seus vastos órgãos funcionando poderosamente. Nem este meu supercivilizado amigo compreendia que longe de armazéns servidos por três mil caixeiros (...) - o homem do século XIX pudesse saborear, plenamente, a delícia de viver! $!^{14}$

A cidade apresenta-se, primeiramente, para Jacinto, como uma visão ideal em oposição às serras, onde toda a intelectualidade se esteriliza. Eça, configurando o trânsito do lirismo de sua pessoa para a persona-protagonista no decorrer da fábula, desenhou a vida urbana tomando como modelo, Paris, essencialmente característica da civilização européia contemporânea. Exagerou, propositalmente, os traços e as cores da metrópole onde morara e que bem conhecia, para deixar a impressão da desvalia da ciência, do desprestígio do progresso material, da indignidade da educação moral e social da grande cidade e, sobretudo, do ridículo de seus banhos e lenços perfumados, de sua efervescência festiva, elegante, requintada e artificial. Paris era para Jacinto, a terra prometida, "(...) Paris lhe dava a sensação tão necessária à vida como o calor da solidariedade humana. (...) Em Portugal era uma tragédia. Não há senão Paris”. ${ }^{15}$

Percebe-se nesse momento da narrativa que a apologia à cidade, ao progresso, à fartura, à mecânica, à erudição e à civilização, que a princípio significava a felicidade de poder gozar, nas máximas proporções, a vantagem de viver, tanto para os indivíduos como para as nações, começa a transbordar no dia a dia do personagem, como a água transbordara em rebelião contra a subserviência que lhe impuseram o tubo e a torneira do lavabo do 202. A cumplicidade rítmica entre o clima físico (Paris) e o clima humano (Jacinto) entra, gradativamente, no descompasso do amor frustrado. Ele se sente

\footnotetext{
${ }^{13}$ QUEIROZ, [s.d.]. p.11.

${ }^{14}$ QUEIROZ, [s.d.]. p.13.

${ }^{15}$ QUEIROZ, [s.d.]. p.64.
} 
entediado, saturado, deprimido, buscando novas alternativas, novos caminhos:

Então o meu Príncipe, sucumbido, arrastou os passos até ao seu gabinete, começou a percorrer todos os aparelhos completadores e facilitadores da vida - o seu telégrafo, o seu telefone, o seu fonógrafo, o seu radômetro, o seu gramofone, o seu microfone, a sua máquina de escrever, a sua máquina de contar, a sua imprensa elétrica, a outra magnética, todos os seus utensílios, todos os seus tubos, todos os seus fios (...) Assim um suplicante percorre altares de onde espera socorro. E toda a sua suntuosa mecânica se conservou rígida, reluzindo frigidamente, sem que uma roda girasse, nem uma lâmpada vibrasse, para entreter o seu senhor. ${ }^{16}$

Oportunamente o Príncipe do 202 dos Campos Elísios, que cultuara a tecnologia e a modernidade como ideal de vida, sofre um processo de mudança. Da realidade de obsessão pela máquina, brotam o tédio, o pessimismo, a descrença e a depressão. Nem mesmo a requintada comida francesa; a sublime presença das belas madames; as cortesãs de grande pompa; a informação e a erudição acumuladas dos seus mais de trinta mil volumes; e a bajulação das classes dominantes, que lhe comiam as trufas em lautos jantares, conseguiam reanimá-lo. Ironicamente é o Grilo, o venerando criado preto, quem, em sua simplicidade, diagnostica os males do herói, "- Sua excelência sofre de fartura". ${ }^{17}$

Jacinto é um homem blasé, um homem atormentado e que padece, mas "apesar do apetite embotado por doze anos de champagnes e molhos ricos, ele conserva a rijeza de pinheiro bravo" 18 herdada da raça fortíssima dos velhos antepassados. Carrega ainda consigo a ideologia dândi, que lhe confere a necessidade de combater, ou mesmo de destruir o que é trivial, participando do mesmo caráter de oposição e de revolta, representante, muitas vezes,

\footnotetext{
${ }^{16}$ QUEIROZ, [s.d.]. p.61.

${ }^{17}$ QUEIROZ, [s.d.]. p.46.

${ }^{18}$ QUEIROZ, [s.d.]. p.57.
} 
de uma faceta positiva do orgulho humano. Jacinto é fruto de uma época de transição, na qual a democracia é frágil e a aristocracia é aviltada. O dandismo surge nele, não como um gosto sem medida pela sociedade, pela moda e pela elegância material, mas como um índice da superioridade aristocrática do seu espírito, já que é produto de um temperamento cuidadosamente cultivado, visando à beleza do bem-vestir, à flor perfeita da elegância exterior que, como arte, é, na verdade, uma busca incoerente de um ideal maior.

Nessa mesma esteira, Baudelaire, ao relacionar a postura moral com o ideal artístico, não aceita a submissão do belo ao útil, mas admite, sim, a forma inversa, isto é, que a vida se organize em direção à harmonia e à beleza, e o ético submeta-se ao estético. Para o poeta francês, a moral que convém ao artista é a do dândi, ou seja, o culto de si mesmo em busca do amor, da saúde, da higiene, da toalete, da nobreza espiritual e da eloqüência. $\mathrm{O}$ dandismo baudelairiano está, não apenas na raiz da fundamentação teórica produzida por esse autor, mas, até mesmo, na origem e na justificação de sua conduta humana e social. Recorra-se ao próprio escritor francês para que se entenda melhor essa instigante e paradoxal postura diante da vida e da arte. O que seria exatamente o dândi e a sua significação?

Para Baudelaire - como para Pascal - a natureza estaria corrompida pela própria natureza. Ambos postulam que o natural em relação à saúde, à toalete e à higiene é abominável e anti-humano. Para eles, também, o importante é o gesto, não necessariamente a finalidade. No processo, o gesto torna-se mais valioso do que a própria finalidade. O dândi é um ator que representa para os outros e, mais ainda, para si próprio. Sua máscara, se por um lado é artifício, por outro é defesa que lhe aderiu à pele para sempre e tão profundamente que não mais lhe é possível arrancá-la. O fundamental a ser cultivado é a consciência do que deve ser vivido. Visto desse ângulo, o dandismo baudelairiano é, sobretudo, uma manifestação do espírito, um processo de vida interior, cujas raízes e implicações são bem mais profundas do que a princípio se possa imaginar. É justamente nesse sentido, nessa teoria e nesse rito que se enquadra o Príncipe Jacinto. 
Assim como Baudelaire, Eça de Queiroz, na missiva enviada pelo administrador Silvério, faz uma "Invitation au Voyage" ("Convite à Viagem"). Nas "Correspondances" ("Correspondências") o poeta vislumbrara e criara a natureza através da narrativa. Por sua vez, Jacinto, ao receber uma correspondência de Portugal, informandolhe que as obras da capela nova estariam em breve prontas para receber "os venerandos restos dos excelsos avós", ${ }^{19}$ decide num rasgo de escrúpulo, de decência, de honra e de elegância ética própria do dândi: "- Zé Fernandes, vou partir para Tormes". ${ }^{20}$ Mas sua decisão inclui transportar consigo, além de suas vinte e três malas, todas as vantagens possíveis e o conforto de Paris, para gozálos nas serras.

O deslocamento de Jacinto realiza-se em dois planos justapostos: primeiro o objetivo-físico, com o Príncipe abandonando a França em direção a Portugal; e depois o subjetivo-emocional, no qual o dândi urbano abre espaço para o outro, sui generis, reformulado e revigorado pelas serras. O primeiro plano é aparente e perceptível porque se concretiza na paisagem; o segundo disfarça-se enquanto se volatiliza na personalidade de Jacinto. Com a viagem inicia-se o movimento geográfico da provação do herói, durante o qual ele primeiro sofre e lamenta a perda de sua bagagem e dos caixotes de civilização remetidos de Paris, para depois, envolto pela reconstrução paisagística queiroziana, perceber a natureza - a robustez e a fartura das oliveiras, a alface rechonchuda e crespa, os vetustos carvalhos plantados por vetustos Jacintos, o aroma dos cravos, as maçãs verdes, as sebes carregadas de amoras, os rouxinóis dos laranjais e a comunhão com os astros - como a suprema arte da criação. A ética de ser do dândi citadino é sobrepujada pela sua estética serrana de sentir. Jacinto passa-se a limpo, modifica-se, conquistando um novo tom, um novo estilo que, na verdade, não era tão novo assim, pois jazia latente no íntimo de sua personalidade portuguesa, haja vista

${ }^{19}$ QUEIROZ, [s.d.]. p.62.

${ }^{20}$ QUEIROZ, [s.d.]. p.62. 
a sua aceitação e valorização imediata da cozinha de Tormes: do perfumado caldo de galinha fervido com o fígado e a moela, do louro frango assado no espeto, da salada regada com um azeite digno dos lábios de Platão. O motivo caracterizador deste mais recente Jacinto, representado pela mudança do espaço geográfico e pelo ambiente das serras, homologa, estimula e confirma a renovação, uma verdadeira ressurreição do espírito e da alma do personagem e sua encarnação em "homem do campo":

Jacinto já não corcovava. Sobre a sua arrefecida palidez de supercivilizado, o ar montesino, ou vida mais verdadeira, espalhara um rubor trigueiro e quente de sangue renovado que o virilizava soberbamente. Dos olhos, que na cidade andavam sempre tão crepusculares e desviados do mundo, saltava agora um brilho de meiodia, resoluto e largo, contente em se embeber da beleza das coisas. Até o bigode se lhe encrespara. E já não deslizava a mão desencantada sobre a face, - mas batia com ela triunfalmente na coxa. Que sei? Era um Jacinto novíssimo. E quase me assustava, por eu ter de aprender e penetrar, neste novo Príncipe, os modos e as idéias novas. ${ }^{21}$

O herói português, dessa forma, não é por excelência o dândi baudelairiano. Jacinto apresenta características peculiares dos Jacintos medievais, devido à seleção de cores e tintas com que foi pintado. Eça, ficcionista, divide esse papel com o memorialista, o idealista, o autobiógrafo, quando, por meio de uma linguagem irônica, constrói o dândi lusitano e, usando a voz do protagonista, declara que "Sim, é talvez tudo uma ilusão... E a cidade a maior ilusão!”. ${ }^{22}$ Uma ilusão perversa, porque é nela, José Fernandes acrescenta, que o homem perde "a força e a beleza harmoniosa do corpo (...) e se torna esse ser em que Deus, espantado, mal pôde reconhecer o seu esbelto e rijo e nobre Adão!”. ${ }^{23}$

${ }^{21}$ QUEIROZ, [s.d.]. p.84.

${ }^{22}$ QUEIROZ, [s.d.]. p.48.

${ }^{23}$ QUEIROZ, [s.d.]. p.48. 
Os escritores, de alguma forma, projetam-se nos seus personagens, sejam eles históricos ou imaginários. Sendo assim, Jacinto, ao refletir sobre o significado da existência do homem na terra e na transcendência da vida, mesmo tendo personalidade portuguesa própria, por vezes assume postura coincidente à vivência do seu criador, resultado que é de combinações e procedimentos situados num mesmo tempo e espaço. Seu dandismo, como argumentado, transcende os limites geográficos urbanos, território típico do flaneur. Ao transferir-se da metrópole para o campo, o herói não se deixa simplesmente modelar pela conduta ajustada ao novo ambiente. Na verdade é a serra que, de certa forma, aproxima-se da cidade, para servir, assim como a vestimenta, ao seu temperamento dândi, refletindo, em sentido inverso, as palavras de Walter Benjamin no momento em que o filósofo alemão explica que

A teoria da transmutação da cidade em zona rural: era (...) a tese principal do meu trabalho inacabado sobre Maupassant. Nela se tratava a cidade como zona de caça, mas nela, sobretudo, o conceito do caçador desempenhava um papel relevante (por exemplo, para uma teoria da uniformidade: todos os caçadores se assemelham). ${ }^{24}$

Tanto em Paris, quanto em Tormes, Jacinto, personagem plano, conserva a marca quixotesca do dândi caçador de "ideais", voltando com ardor a seus projetos de introduzir nas serras uma cultura de luxo, oficinas elegantes e magnificências rurais. Dessa forma transporta consigo o leitor para além dos limites urbanos, até a amplitude dos montes que a ele se adapta. O simbolismo da montanha é múltiplo: é a altura e o centro, e no encontro da terra com o céu figura a transcendência. As serras são também vistas como signo da grandiosidade e da pretensão humana que não escapa, entretanto, ao poder divino. Simbolizam ainda a função psíquica do subconsciente, que conduz o homem ao ápice de seu desenvolvimento. Mas as serras de Tormes não retratam unicamente um sítio fértil e irrigado, ensolarado e paradisíaco, coberto de flores e árvores protetoras,

${ }^{24}$ BENJAMIN, 1994. p.188. 
isento de cercas e de limites, privilegiado por eterna primavera. Lá existe a fome, a insalubridade, a pobreza, a doença para desmistificar a construção do imperativo paradisíaco do campo, imposto pela ideologia romântica.

Eça de Queiroz proporciona ao leitor de $A$ cidade e as serras momentos de densa reflexão sobre o espaço e seu equipamento de coisas na obra literária, à medida que pontua e articula, numa espécie de sistema binário, as diferenças sócio-comportamentais entre indivíduos de ambientes diferentes. Esse escritor emérito, perscrutador enfático do elemento lugar na ficção moderna, ressalta a bivalência entre o rural e o urbano por meio de marcas geográficas ostensivas, e, utilizando-se da narrativa descritiva funcional realista, fixa, fotograficamente, as paisagens naturais e as da metrópole, onde se desenvolvem as aventuras dos heróis:

Hem, Jacinto?... Onde estão os teus armazéns servidos por três mil caixeiros? E os bancos em que retine o ouro universal? E as bibliotecas atulhadas com o saber dos séculos? Tudo se fundiu numa nódoa parda que suja a terra. Aos olhos piscos de um Zé Fernandes, logo que ele suba, fumando o seu cigarro, a uma arredada colina - a sublime edificação dos tempos não é mais que um silencioso monturo de espessura e da cor do pó final. O que será então aos olhos de Deus! ${ }^{25}$

Entretanto seu personagem principal, estando em Tormes e sendo português, preserva-se tão autêntico dândi como o fora em Paris, conservando as mesmas vertentes características desse tipo, isto é, um interesse pela imprensa - agora por jornais de agricultura uma moral estóica, um comportamento social aristocrático isento de vulgaridades, uma atitude estética própria do artista em busca da perfeição. Fica claro que, na obra, os signos lingüísticos utilizados para marcar a riqueza psicológica de Jacinto e Zé Fernandes, ambos intrinsecamente portugueses, competem com a densidade e relevância das anotações espaciais para sobrepujá-las.

${ }^{25}$ QUEIROZ, [s.d.]. p.48. 
Assim sendo, esse verdadeiro e ambivalente dândi, atrigueirado nas soalheiras e nos ventos da serra (...) e eu, tão longe de amarguradas ilusões e de falsas delícias, trilhando um solo eterno, e de eterna solidez, com a alma contente, e Deus contente de nós, serenamente e seguramente subíamos - para o Castelo da GrãVentura! ${ }^{26}$

seguindo os passos e o exemplo dos velhos Jacintos medievais.

A trilha e a trajetória dos heróis não são, como já mencionado, uma questão só de espaço, mas também de tempo real e psicológico. Não se dá, na fábula, uma "itinerância" simplesmente física e cronológica, mas, interior e emocional, e portanto temporal, em busca da felicidade. Uma vez concretizada a empatia entre personagem e hábitat, aquele se dignifica e se realiza como dândi lusitano e como gente, retomando, na serra, muito do jeito que parecera renunciar em Paris.

E é sendo assim que o Príncipe, deixando para trás o ambiente e o tempo do deslumbramento nebuloso das "águas oxigenadas, carbonatadas, fosfatadas e esterilizadas" ${ }^{27}$ da metrópole, prepara-se para uma trajetória em direção a um futuro pleno de paz, de lindeza e de reconciliação com a vida, bebendo a água fresca, nevada luzidia e refulgente "de uma fontinha rústica, meio afogada em rosas tremedeiras", ${ }^{28}$ e da fonte velha de Tormes!...

Na realidade, esse Jacinto híbrido e polivalente, que fora "aquele galho ressequido de cidade" 29 lançara raízes rijas na sua rude serra:

Era realmente como se o tivessem plantado de estaca naquele antiqüíssimo chão, de onde brotara a sua raça, e o antiqüíssimo humo refluísse e o penetrasse todo, e o andasse transformando num Jacinto rural, quase vegetal, tão do chão, e preso no chão, como as árvores que ele tanto amava.

${ }^{26}$ QUEIROZ, [s.d.]. p.131.

${ }^{27}$ QUEIROZ, [s.d.]. p.21.

${ }^{28}$ QUEIROZ, [s.d.]. p.76.

${ }^{29}$ QUEIROZ, [s.d.]. p.123. 
E depois de reconciliar-se com a vida; de construir currais elegantes; de plantar uma e muitas árvores; de casar-se com a "prima" Joaninha da casa da Flor da Malva e de ter filhos; de não só contemplar sua propriedade com o enlevo da imaginação, mas também de a trabalhar com o suor do rosto; de descobrir as chagas e a pobreza de sua propriedade em Tormes para tentar curá-las e, graças a tudo isso; de recuperar o dom divino de rir na busca da perfeição da beleza moral, Jacinto, aquele homem que se distinguira outrora pela inquietação filosófica e pelos vários tormentos da fantasia insaciada, está pronto agora para apresentar-se ao julgamento final, com uma rosa branca na lapela, o seu "grande chapéu serrano, a jaqueta", ${ }^{30}$ o colete lavrado e trespassado, a gravata de seda branca presa por uma pérola negra, os sapatos também brancos cobertos de pó e a bengala grossa com castão de cristal... Até às últimas conseqüências.

\section{Referências Bibliográficas}

BAUDELAIRE, Charles. Les fleurs du mal. Paris: Livre de Poche, 1972. BAUDELAIRE, Charles. Sobre a modernidade: o pintor da vida moderna. Teixeira Coelho (Org.) Rio de Janeiro: Paz e Terra, 1996. BENJAMIN, Walter. Charles Baudelaire - um lírico no auge do capitalismo. São Paulo: Brasiliense, 1994.

BECHELARD, Michel. Histoire de la littérature française-XIX siècle. Paris: Hatier, 1989.

BEERBOHM, Max. "Dandies and dandies". In: Internet: http:// www.albany.edu/faculty/rip96/beerbohm.html, 1999.

BEZBAKH, Pierre. L'bistoire de France des origines à 1914. Paris: Bordas, 1989.

${ }^{30}$ QUEIROZ, [s.d.]. p.130. 
BOYER, Bruce. "The return of dandyism". In: Internet: http:// www.forbes.com/Forbes/98/0509/0103248S1.html, 1998.

BOYER, Bruce. "The dandy". In: Internet: http://homepages. mug.com.nz/ awoodley/regency/dandy.html, 2000.

CHEVALIER, Jean \& GHEERBRANT, Alain. Dictionnaire des Symboles. Paris: Robert Laffont \& Jupiter, 1993.

DIMAS, Antônio. Espaço e romance. São Paulo: Ática, 1985.

GOFF, Robert. "Dandy is as dandy does". Internet: http:// www.forbes.com/forbes/98/0509/0103248S1.html, 1998.

HOLMAN, C. Hugh. A handbook to literature. 4.ed. Indianapolis: Bobbs-Merrill,1980.

LAVER, James. A roupa e a moda. São Paulo: Cia das Letras, 1989.

LINS, Álvaro. História literária de Eça de Queiroz. Rio de Janeiro: O Cruzeiro, 1964.

MARX, Karl \& ENGELS, Friedrich. O manifesto comunista. Rio de Janeiro: Paz e Terra, 1997.

QUEIROZ, Eça. A cidade e as serras. Rio de Janeiro: Ediouro, [s.d.]. MOISÉS, Massaud. A literatura portuguesa. São Paulo: Cultrix, 1968. SANTOS, Francisco José W. As idéias de Eça de Queiroz. Rio de Janeiro: Agir, 1946. 


\section{Resumo}

Este ensaio estuda a ideologia do dandismo, originário da Inglaterra no século XIX, para focalizar, em Jacinto de Tormes, protagonista do romance $A$ cidade $e$ as serras, de Eça de Queiroz, as manifestações de superposição e semelhança origem, aparência, comportamento político e social - com as do dândi baudelairiano. O trabalho demonstra que Jacinto apresenta uma identidade indubitavelmente portuguesa, e que não pode ser visto como um mero estereótipo do fenômeno em questão.

\section{Abstract}

This essay studies the ideology of dandyism - which emerges in the $19^{\text {th }}$ century England - in order to analyze Jacinto de Tormes, the protagonist of $A$ cidade $e$ as serras by Eça de Queiroz. The analysis focuses on the manifestations of superposition and similarity of origin, appearance, political and social behavior revealed in Eça's character and in the baudelairian dandy. The conclusion demonstrates that Jacinto presents an undoubted Portuguese identity, and that he cannot be seen as a mere stereotype of the dandy. 